Post-print of: Food Chemistry 172. 559-564 (2015)

\title{
Use of near infrared hyperspectral tools for the screening of extractable polyphenols in red grape skins
}

\author{
Julio Nogales-Bueno, Berta Baca-Bocanegra, Francisco José Rodríguez-Pulido, Francisco José Heredia, \\ José Miguel Hernández-Hierro*
}

Food Colour and Quality Laboratory, Department of Nutrition and Food Science, Facultad de Farmacia, Universidad de Sevilla, 41012 Sevilla, Spain

\begin{abstract}
A B S T R A C T
Hyperspectral images of intact grapes were recorded at harvest time using a near infrared hyperspectral imaging system (900-1700 nm). Spectral data have been correlated with red grape skin extractable polyphenols (total phenolic, anthocyanins and flavanols) by modified partial least squares regression (MPLS) using a number of spectral pretreatments. The obtained results (coefficient of determination (RSQ) and standard error of prediction (SEP), respectively) for the developed models were: 0.82 and $0.92 \mathrm{mg} \mathrm{g}^{-1}$ of grape skin for extractable total phenolic content, 0.79 and $0.63 \mathrm{mg} \mathrm{g}^{-1}$ of grape skin for extractable anthocyanin content, 0.82 and $0.45 \mathrm{mg} \mathrm{g}^{-1}$ of grape skin for extractable flavanol content. The obtained results present a good potential for a fast and reasonably inexpensive screening of the extractable polyphenolic compounds in intact grapes. Moreover, the heterogeneity of extractable polyphenols within the ripeness stage has been also evaluated using the proposed method.
\end{abstract}

Extractable polyphenols

Anthocyanins

Flavanols

Grapes

Near infrared hyperspectral imaging

Chemometrics

\section{Introduction}

Red grapes (Vitis vinifera L.) contain about four grams of phenolic material per kilo. There is substantial variation in levels of phenolic compounds which depends on a number of factors including the variety of grape, high or low skin:volume ratio, growing region, climate, and growth conditions (Crozier, Clifford, \& Ashihara, 2006). Furthermore, similar heterogeneity can be also found within the same physiological stage. Some studies describe a Gaussian bell-shaped distribution of soluble solids and extractable total phenolic content in a sampling point (Kontoudakis et al., 2011; Zouid, Siret, Jourjon, Mehinagic, \& Rolle, 2013).

Wine and grape phenolic compounds are grouped into two categories, flavonoids and non-flavonoids. The flavonoids are all polyphenolic compounds, having multiple aromatic rings possessing

Abbreviations: DMACA, p-dimethylaminocinnamaldehyde; EAC, extractable anthocyanin content; EFC, extractable flavanol content; EPC, extractable total phenolic content; $H$, Mahalanobis distance; MPLS, modified partial least squares; MSC, multiplicative scatter correction; NH, neighbourhood Mahalanobis distance; NIRS, near infrared spectroscopy; PC, principal component; PCA, principal component analysis; PLS, partial least squares; RSQ coefficient of determination; SEC, standard error of calibration; SECV, standard error of cross-validation; SEP, standard error of prediction; SNV, standard normal variate.

* Corresponding author. Tel.: +34 9545 56761; fax: +34 954557017.

E-mail address: jmhhierro@us.es (J.M. Hernández-Hierro). hydroxyl groups. The majority of flavonoids in red grapes are found in seeds and berry skin and are transferred to the wine from the above mentioned parts during the fermentation process. Among these compounds, flavanols constitute the most abundant class and play a relevant role in the sensory characteristic of red wines whereas anthocyanins are red-coloured phenols that give to red wine its characteristic colour (Waterhouse, 2002). The main nonflavonoids are hydroxycinnamic acids, benzoic acids, hydrolyzable tannins and stilbenes (Harborne, 1994). The origin of the nonflavonoids in wine is more diverse. In grapes and wines not aged in oak, the primary non-flavonoids are derivatives of hydroxycinnamic and hydroxybenzoic acids. They are stored primarily in cell vacuoles of skin and pulp, and are easily extracted on the crushing stage (Jackson, 2000). The influence of phenols (flavonoids or nonflavonoids) in the antioxidant activity of wines has been previously reported (Rice-Evans, Miller, \& Paganga, 1997).

Winemakers are continuously looking for high quality wines. One of the major factors affecting wine quality is grape phenolic maturity (Ribéreau-Gayon et al., 2006). This factor shows the amount of phenolic compounds in the skin, pulp and/or seed. It is also really important to know the amount of these phenols that may be extracted from grapes to wine. The extractability of phenolic compounds from skins depends significantly on grape ripeness. Riper grapes have higher cell wall degradation hence they have higher extraction degree (Hernández-Hierro et al., 2014; 
Ribéreau-Gayon et al., 2006). Thus, it is possible to find studies linking phenol extractability to some factors related to grape ripeness. In grape skin, the extracted phenolic compounds (total phenols, total anthocyanins and total flavanols) increase with soluble solids content of grape must (Fournand et al., 2006; Torchio, Cagnasso, Gerbi, \& Rolle, 2010; Zouid et al., 2013). In addition, different stages of ripening concern the amount of extractable phenols in the same way that total soluble solids (Canals, Llaudy, Valls, Canals, \& Zamora, 2005; Fournand et al., 2006; HernándezHierro, Quijada-Morín, Rivas-Gonzalo, Rivas-Gonzalo, \& Escribano-Bailón, 2012). Finally, this parameter is also linked to grape maceration conditions (González-Manzano, Rivas-Gonzalo, \& Santos-Buelga, 2004).

In the abovementioned studies, extractions of different phenols from grape skin were carried out using wine simulated macerations. This technique needs to remove skins manually from the pulp and then immerse them in a model wine hydroalcoholic solution. After a maceration period (around 3-5 days) the supernatant is used for spectrophotometric and chromatographic analysis. Taking that into account, the determination of the amount of the extracted phenols is a destructive and time consuming process.

In previous works carried out in our laboratory, hyperspectral imaging has been used to develop screening methods in order to measure phenols concentration in grape or grape seeds. Hernández-Hierro, Nogales-Bueno, Rodríguez-Pulido, and Heredia (2013) carried out a screening method to determine the total content of anthocyanins in grapes during ripening for Syrah and Tempranillo varieties. Nogales-Bueno, Hernández-Hierro, RodríguezPulido, and Heredia (2014) used this technology for the screening of $\mathrm{pH}$, total acidity and sugar concentration of must and total phenols concentration in skins of white and red grapes. Finally, hyperspectral imaging has also been used for the screening of total and extractable flavanols in grape seeds in white and red cultivars as reported by Rodríguez-Pulido et al. (2014).

The main aim of this study is to develop a fast and non-destructive hyperspectral method for the screening of the extractable content of anthocyanins, flavanols and total phenolic compounds in grape skins. To our knowledge, near infrared hyperspectral imaging has been applied to grapes to face these goals for the first time.

\section{Materials and methods}

\subsection{Samples}

V. vinifera L. cv. Syrah and Tempranillo red grape samples were collected from two vineyards located in the Condado de Huelva Designation of Origin D.O. (Andalusia, Spain). Tempranillo is the most often grown red grape cultivar in Spain for producing quality red wines and Syrah is a resistant cultivar to warm climatic conditions. Syrah represents an important percentage of the grown red grape under the aforementioned climatic conditions (Gordillo et al., 2012).

Tempranillo and Syrah grapes were collected when the vineyards were harvested (August 12 and 27, 2013 respectively). One hundred single berries were collected for each variety. In order to achieve representative samples sets, these were collected from the top, middle and bottom of the cluster and in the sunlight and shade side of this. After that, the samples were refrigerated and they were immediately carried to the laboratory, tempered and subjected to the hyperspectral analysis.

\subsection{Hyperspectral image acquisition}

Hyperspectral imaging device (Infaimon S.L., Barcelona, Spain) comprised a Xenics ${ }^{\circledR}$ XEVA-USB InGaAs camera $(320 \times 256$ pixels;
Xenics Infrared Solutions, Inc., Leuven, Belgium), a spectrograph (Specim ImSpector N17E Enhanced; Spectral Imaging Ltd., Oulu, Finland) covering the spectral range between 900 and $1700 \mathrm{~nm}$ (spectral resolution of $3.25 \mathrm{~nm}$ ). The individual hyperspectral image of each grape was recorded. Equipment and procedure used to image recording are described in detail elsewhere in HernándezHierro et al. (2013).

After calibration and segmentation processes, the average spectral profile for each grape was saved. Noisy wavebands at both extremes of the spectra range were removed and only spectral data in the resulting effective wavelength $950-1650 \mathrm{~nm}$ regions were used in data analysis due to reduced efficiency outside this range in the used device.

\subsection{Determination of reference parameters}

Grape skins were separated manually from the whole grapes and they were weighted, then grape skins were immediately frozen and stored an $-20^{\circ} \mathrm{C}$ until analysis were performed. Reference parameters taken into account were extractable total phenolic content, extractable anthocyanin content and extractable flavanol content in grape skin. Grape skins were immersed in a model wine hydroalcoholic solution $\left(4 \mathrm{~g} \mathrm{~L}^{-1}\right.$ tartaric acid, $12.5 \%$ ethanol, adjusted at $\mathrm{pH} 3.6$ with $\mathrm{NaOH} 0.5 \mathrm{M}$ ) for a maceration period of $72 \mathrm{~h}$. This supernatant was used in all the following reference analysis.

Extractable total phenolic content was determined using the Folin-Ciocalteu method (Singleton, 1985). For quantification, results were expressed as $\mathrm{mg}$ of gallic acid equivalents per gram of grape skin.

In order to measure the extractable anthocyanin content, the supernatant was diluted $1: 2$ with $0.1 \mathrm{M} \mathrm{HCl}$, filtered through $0.45 \mu \mathrm{m}$ pore size filters and directly injected into the chromatographic system. Anthocyanin chromatographic analysis was carried out following a modification of García-Marino, HernándezHierro, Rivas-Gonzalo, and Escribano-Bailón (2010) as described elsewhere in Hernández-Hierro et al. (2013). Results were expressed as mg of malvidin-3-O-glucoside equivalents per gram of grape skin. All analyses were performed in duplicate. The standard error was generally around $10 \%$ so the error and degree of accuracy of the reference method was considered appropriate to use these data as reference values.

Extractable flavanol content was determined following a modification of Vivas, Glories, Lagune, Saucier, and Augustin (1994). Ten microlitres of supernatant was mixed with $190 \mu \mathrm{L}$ of methanol and $1 \mathrm{~mL}$ of p-dimethylaminocinnamaldehyde (DMACA) reagent. The absorbance was recorded at $640 \mathrm{~nm}$ after $10 \mathrm{~min}$ of reaction. This measure was performed in duplicate on an Agilent 8453 UV-visible spectrophotometer (Palo Alto, USA), equipped with diode array detection (DAD). A calibration curve of (+)-catechin (SigmaAldrich, St. Louis, USA) for quantification and all the measures were within the linear range of the calibration curve. All the results were expressed as mg of catechin equivalents per gram of grape skin.

\subsection{Data analysis}

An unsupervised pattern recognition technique, principal component analysis (PCA), was used in order to provide information about the latent structure of spectral matrix and to find spectral differences among all spectral samples. This method provides not only information related to spectral outliers and the distribution of samples in the newly-created space, but is also an important source of knowledge with which to create cross-validation groups used in the calibration process (Shenk \& Westerhaus, 1995; Brereton, 2003). PCA was also used to select representative samples from the spectral data set. Mahalanobis distances $(H)$ for each 
sample were calculated and samples were grouped according their neighbourhood $H$ values ( $\mathrm{NH}$ ).

Using the raw spectral data, testing different spectral pretreatments and allocating the corresponding extractable total phenolic content, extractable anthocyanin content and extractable flavanol content to each sample, calibrations were performed by modified partial least squares regression (MPLS). In this method, the group of calibration samples is divided into a series of subsets in order to perform cross-validation to set the number of PLS factors, reduce the possibility of overfitting (Shenk \& Westerhaus, 1995) and remove chemical outliers. Using the $T \geqslant 2.5$ criterion, samples that presented a high residual value when they were predicted were eliminated from the set. Finally, validation errors are combined into a single figure, the standard error of cross-validation (SECV).

Spectral pretreatments are usually applied to NIR raw data. Scattering effects were removed using multiplicative scatter correction (MSC), standard normal variate (SNV), and detrending (Dhanoa, Lister, \& Barnes, 1995; Geladi, MacDougall, \& Martens, 1985). Moreover, the effect of differentiation and variations in spectral ranges were tested in the development of the NIRS calibrations.

The software used was Win ISI ${ }^{\circledR}$ (v1.50) (Infrasoft International, LLC, Port. Matilda, PA, USA). This software allowed the data pretreatment, principal components analysis and sample selection and development of quantitative models.

\section{Results and discussion}

\subsection{Sample selection}

Sample selection was made in order to reduce the number of samples maintaining as much spectral variety as possible. To keep
Table 1

Main statistical descriptors for reference parameters in calibration and validation sets.

\begin{tabular}{llllll}
\hline Set & $\begin{array}{l}\text { Reference } \\
\text { parameters }\end{array}$ & Maximum & Mean & Minimum & SD $^{\mathrm{a}}$ \\
\hline Calibration & EPC $^{\mathrm{b}}$ & 7.50 & 4.24 & 1.41 & 1.52 \\
& EAC $^{\mathrm{c}}$ & 4.09 & 1.73 & 0.28 & 0.91 \\
& EFC $^{\mathrm{d}}$ & 3.49 & 1.33 & 0.40 & 0.73 \\
Validation & EPC $^{\mathrm{b}}$ & 7.41 & 4.18 & 1.61 & 1.48 \\
& EAC $^{\mathrm{c}}$ & 3.17 & 1.72 & 0.97 & 0.58 \\
& EFC $^{\mathrm{d}}$ & 2.91 & 1.41 & 0.44 & 0.69 \\
\hline
\end{tabular}

a SD: standard deviation.

b EPC: extractable total phenolic content $\left(\mathrm{mg} \mathrm{g}^{-1}\right.$ of skin grape, expressed as gallic acid equivalents).

c EAC: extractable anthocyanin content $\left(\mathrm{mg} \mathrm{g}^{-1}\right.$ of skin grape, expressed as malvidin-3-O-glucoside equivalents).

d EFC: extractable flavanol content $\left(\mathrm{mg} \mathrm{g}^{-1}\right.$ of skin grape, expressed as catechin equivalents).

as much spectral information as possible, this selection was carried out from a PCA. A SNV $(2,5,5,1)$ spectral pre-treatment was applied to the spectra of all samples in the $950-1650 \mathrm{~nm}$ region, where the hyperspectral system has revealed greater efficiency. Mathematical treatment is denoted as a,b,c,d, where the first digit is the number of the derivative; the second is the gap over which the derivative is calculated; the third is the number of data points in a running average or smoothing, and the fourth is the second smoothing (Shenk \& Westerhaus, 1995).

Using all spectral samples, five principal components were taken into account. Ninety per cent of the spectral variability of original spectral matrix was explained. Moreover, three spectral outliers were found and removed from this matrix. In this fivedimensional space the 197 samples were grouped according a

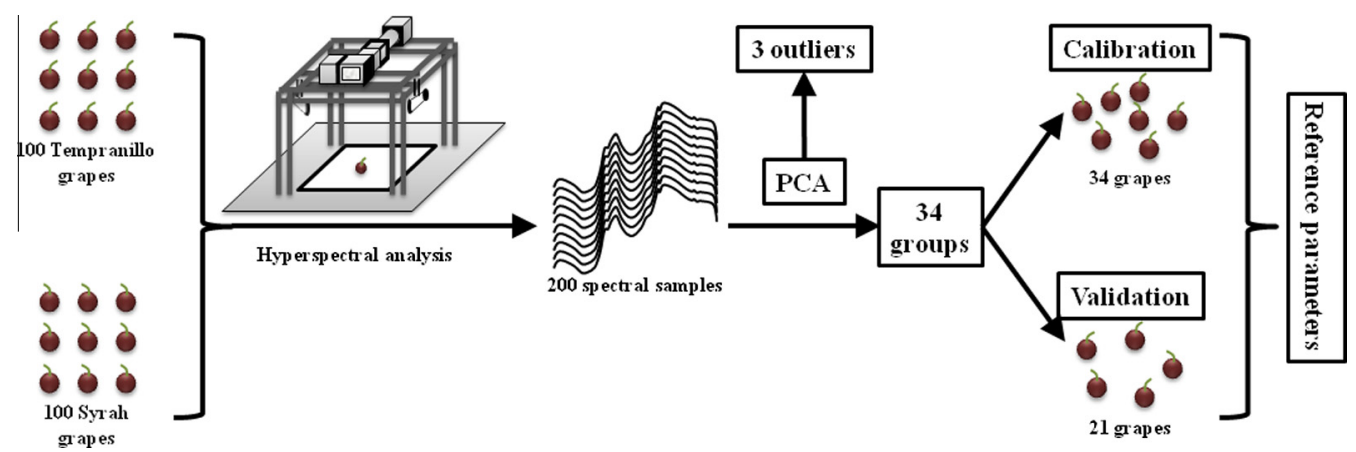

Fig. 1. Graphical description of the sample selection process.

a

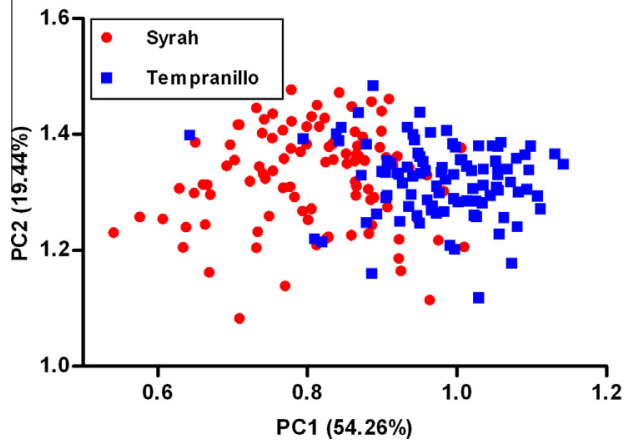

b

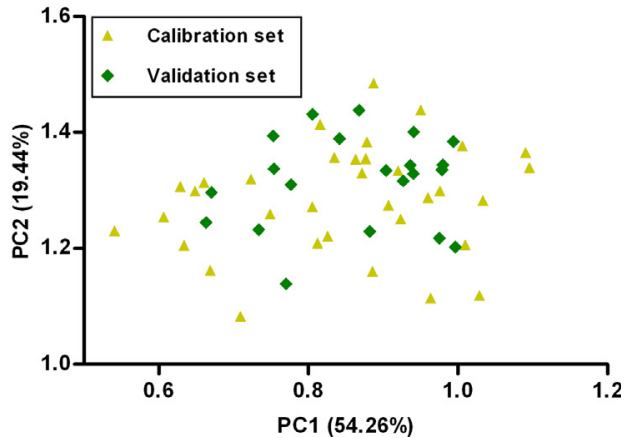

Fig. 2. Score plot of grape samples in the space defined by PC1 and PC2. (a) Codified as Syrah and Tempranillo grapes. (b) Codified as calibration and validation sets. 
Table 2

Calibration statistical descriptors for the models developed in the NIR zone close to 950-1650 nm.

\begin{tabular}{|c|c|c|c|c|c|c|c|c|c|c|c|}
\hline \multirow[t]{2}{*}{ Spectral pretreatments } & \multirow[t]{2}{*}{ Reference parameters } & \multirow[t]{2}{*}{$T$ outliers } & \multirow[t]{2}{*}{ PLS factors } & \multirow[t]{2}{*}{$N^{\mathrm{a}}$} & Est. min & $\mathrm{SD}^{\mathrm{b}}$ & Est. max & $\mathrm{SEC}^{\mathrm{C}}$ & $\mathrm{RSQ}^{\mathrm{d}}$ & $\mathrm{SECV}^{\mathrm{e}}$ & $\mathrm{SEP}^{\mathrm{f}}$ \\
\hline & & & & & \multicolumn{5}{|c|}{$\left(\mathrm{mg} \mathrm{g}^{-1}\right.$ skin $)$} & \multicolumn{2}{|c|}{$\left(\mathrm{mg} \mathrm{g}^{-1}\right.$ skin $)$} \\
\hline SNV and detrend $1,5,5,1$ & $\mathrm{EPC}^{\mathrm{g}}$ & 1 & 5 & 33 & 0 & 1.53 & 8.86 & 0.65 & 0.82 & 0.92 & 0.92 \\
\hline MSC $1,5,5,1$ & $\mathrm{EAC}^{\mathrm{h}}$ & 1 & 6 & 33 & 0 & 0.92 & 4.50 & 0.42 & 0.79 & 0.62 & 0.63 \\
\hline Detrend 2,5,5,1 & $\mathrm{EFC}^{\mathrm{i}}$ & 2 & 4 & 32 & 0 & 0.64 & 3.21 & 0.28 & 0.82 & 0.50 & 0.45 \\
\hline
\end{tabular}

a $\mathrm{N}$ : number of samples (calibration set).

b SD: standard deviation.

c SEC: standard error of calibration.

d RSQ: coefficient of determination (calibration set).

e SECV: standard error of cross-validation (7 cross-validation groups).

$\mathrm{f}$ SEP: standard error of prediction (external validation).

g EPC: extractable total phenolic content ( $\mathrm{mg} \mathrm{g}^{-1}$ of skin grape, expressed as gallic acid equivalents).

h EAC: extractable anthocyanin content ( $\mathrm{mg} \mathrm{g}^{-1}$ of skin grape, expressed as malvidin-3-O-glucoside equivalents).

${ }^{\mathrm{i}}$ EFC: extractable flavanol content ( $\mathrm{mg} \mathrm{g}^{-1}$ of skin grape, expressed as catechin equivalents).
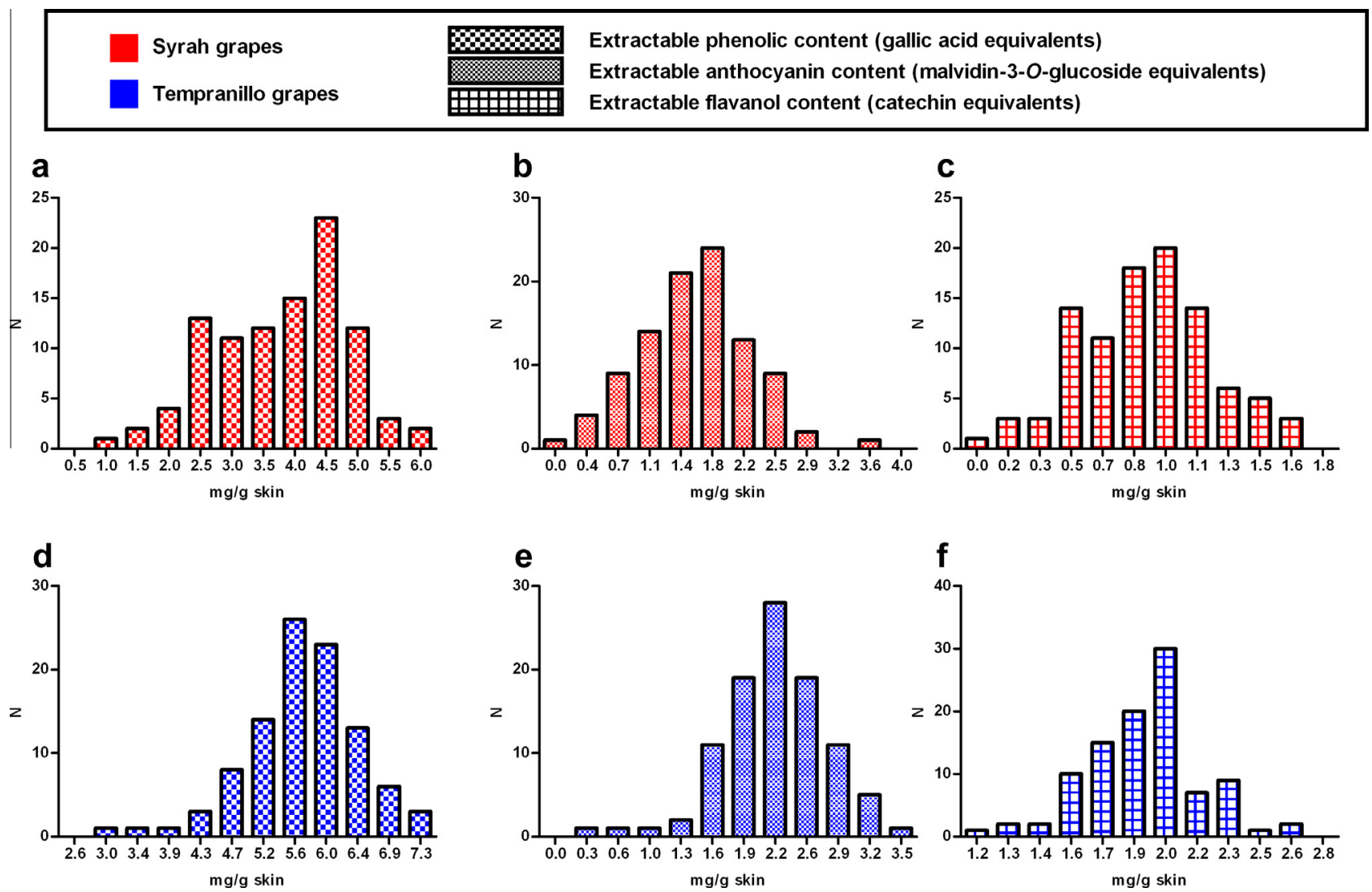

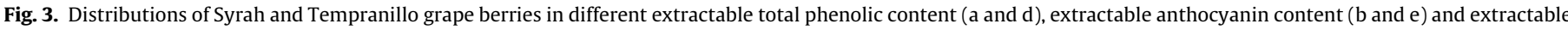
flavanol content ( $\mathrm{c}$ and $\mathrm{f}$ ).

$\mathrm{NH} \leqslant 0.6$ criterion. So, 34 groups with different spectral characteristics were created and one sample from every group was selected to develop a calibration process.

In addition, to create the validation set, another sample from every group was selected. Only 21 samples were allocated in this set because 13 out of 34 groups created had not more than one sample (Fig. 1).

Fig. 2 shows the scores of the grape samples in the space defined by the first and second principal components which described $54.26 \%$ (PC1) and $19.44 \%$ (PC2) of the spectral variability in the data. PC1 could be used to separate the samples according to the cultivar although this separation would not be complete (Fig. 2a). Fig. 2b shows the scores of the calibration and validation samples in the space defined by PC1 and PC2. This space is not entirely the same as the space used to select the calibration and validation sets (bearing in mind that 5 PCs were used). However, in this figure, it can be appreciated how the calibration set includes almost all the spectral variability of samples and therefore, validation set is also included on it.

\subsection{Chemical analysis}

Table 1 shows the main statistical descriptors for the reference parameters of the samples allocated in the calibration and validation sets. These statistical indicators show that chemical variability is bigger in calibration set than in validation one. These results are surely linked with the spectral relationship between both sample sets. 


\subsection{Calibration process}

Quantitative calibrations were developed by modified partial least squares (MPLS) regression. As described above, to perform this calibration 34 grape spectra were used as the independent $(X)$ variables. Extractable total phenolic content, extractable anthocyanin content and extractable flavanol content in grape skin were used as dependent $(Y)$ variables. The statistical parameters of the final calibration equations are shown in Table 2 where $N$ is the number of samples used to obtain the calibration equation after eliminating samples for chemical reasons ( $T$ criterion). The best of the different mathematical treatments, the range of application, and standard deviations are also shown.

The robustness of the selected models was tested using validation set samples, which did not belong to the calibration set, as external validation. For all reference parameters, all samples presented reference values within the applicability of the obtained models. As result of this external validation the standard errors of prediction (SEP) were obtained for each reference variable, these values were also included in Table 2 . These values are comparatively similar to the errors previously reported for total or extractable content of these compounds using near infrared spectroscopy taking into the account the applicability range (Cozzolino, 2009; Ferrer-Gallego, Hernández-Hierro, Rivas-Gonzalo, \& EscribanoBailón, 2011; Hernández-Hierro et al., 2013; Nogales-Bueno et al., 2014; Rodríguez-Pulido et al., 2014).

\subsection{Use of developed methods for the screening of extractable polyphenols}

The methods developed in the preceding section were used to predict the extractable content of total phenols, total anthocyanins and total flavanols in all grape sets. The results show that all three parameters describe a Gaussian bell-shaped distribution for each variety (Fig. 3). This confirms the heterogeneity found within the same ripeness stage for the abovesaid parameters.

Table 3 shows main statistical descriptors for the predicted values in Syrah and Tempranillo samples. In all cases the extractable content of total phenols, anthocyanins and flavanols is higher in Tempranillo grapes than Syrah grapes. This could be due to physicochemical differences between the two varieties. In addition, in typical warm climate regions Tempranillo grapes are harvested with a high ripeness degree of skins in order to achieve an appropriate ripeness degree of seeds (Gordillo, Cejudo-Bastante, Rodríguez-Pulido, González-Miret, \& Heredia, 2013). Thus, these extractable content differences could be due to higher cell wall degradation in Tempranillo grapes than Syrah grapes.

\section{Table 3}

Main statistical descriptors for predicted values in Syrah $(N=98)$ and Tempranillo $(N=99)$ samples.

\begin{tabular}{llllll}
\hline Variety & Predicted parameter & Maximum & Mean & Minimum & SD $^{\mathrm{a}}$ \\
\hline \multirow{2}{*}{ Syrah } & EPC $^{\mathrm{b}}$ & 5.95 & 3.79 & 0.85 & 1.08 \\
& EAC $^{\mathrm{c}}$ & 3.67 & 1.59 & 0.02 & 0.62 \\
& EFC $^{\mathrm{d}}$ & 1.65 & 0.87 & 0.02 & 0.35 \\
\multirow{5}{*}{ Tempranillo } & EPC $^{\mathrm{b}}$ & 7.26 & 5.69 & 2.97 & 0.77 \\
& EAC $^{\mathrm{c}}$ & 3.43 & 2.23 & 0.23 & 0.54 \\
& EFC $^{\mathrm{d}}$ & 2.62 & 1.93 & 1.16 & 0.26
\end{tabular}

a SD: standard deviation.

b EPC: extractable total phenolic content $\left(\mathrm{mg} \mathrm{g}^{-1}\right.$ of skin grape, expressed as gallic acid equivalents)

c EAC: extractable anthocyanin content $\left(\mathrm{mg} \mathrm{g}^{-1}\right.$ of skin grape, expressed as malvidin-3-O-glucoside equivalents).

${ }^{\mathrm{d}}$ EFC: extractable flavanol content ( $\mathrm{mg} \mathrm{g}^{-1}$ of skin grape, expressed as catechin equivalents)

\section{Conclusion}

The procedure reported here using near infrared hyperspectral imaging present a good potential for a fast and reasonably inexpensive screening of the extractable polyphenolic compounds in intact grapes. In addition, the heterogeneity of extractable polyphenols within the same ripeness stage has been observed. This methodology allows to sort the berries according to their polyphenol extractable contents and then the same samples could be used in further studies for other destructive analyses or purposes. Furthermore, differences between Syrah and Tempranillo extractable polyphenols have been also found. Nonetheless, a comprehensive study should be made in order to evaluate factors, such as different production areas and grape varieties, in the complete development of these models.

\section{Acknowledgements}

The Spanish MINECO is thanked for J. Nogales-Bueno FPI grant (BES-2012-060192), J.M. Hernández-Hierro Juan de la Cierva contract (JCI-2011-09201) and project AGL2011-30254-C02. Junta de Andalucía is also thanked for financial support (project P10AGR6331). The authors also thank to technical staff of Biology Service (SGI, Universidad de Sevilla) for the technical assistance.

\section{References}

Brereton, R. G. (2003). Chemometrics: Data analysis for the laboratory and chemical plant. Chichester, West Sussex, England: J. Wiley.

Canals, R., Llaudy, M. C. Valls, J., Canals, J. M. \& Zamora, F. (2005). Influence of ethanol concentration on the extraction of color and phenolic compounds from the skin and seeds of Tempranillo grapes at different stages of ripening. Journal of Agricultural and Food Chemistry, 53, 4019-4025.

Cozzolino, D. (2009). Near infrared spectroscopy in natural products analysis. Planta Medica, 75.

Crozier, A., Clifford, M. N., \& Ashihara, H. (2006). Plant secondary metabolites. Occurrence, structure and role in the human diet. Garsington Road, Oxford, UK: Blackwell Publishing.

Dhanoa, M. S., Lister, S. J., \& Barnes, R. J. (1995). On the scales associated with nearinfrared reflectance difference spectra. Applied Spectroscopy, 49.

Ferrer-Gallego, R., Hernández-Hierro, J. M., Rivas-Gonzalo, J. C., \& Escribano-Bailón, M. T. (2011). Determination of phenolic compounds of grape skins during ripening by NIR spectroscopy. LWT-Food Science and Technology, 44, 847-853.

Fournand, D. Vicens, A., Sidhoum, L., Souquet, J. M., Moutounet, M., \& Cheynier, V. (2006). Accumulation and extractability of grape skin tannins and anthocyanins at different advanced physiological stages. Journal of Agricultural and Food Chemistry, 54, 7331-7338.

García-Marino, M., Hernández-Hierro, J. M., Rivas-Gonzalo, J. C., \& Escribano-Bailón, M. T. (2010). Colour and pigment composition of red wines obtained from comaceration of Tempranillo and Graciano varieties. Analytica Chimica Acta, 660.

Geladi, P., MacDougall, D., \& Martens, H. (1985). Linearization and scattercorrection for near-infrared reflectance spectra of meat. Applied Spectroscopy, 39.

González-Manzano, S., Rivas-Gonzalo, J. C., \& Santos-Buelga, C. (2004). Extraction of flavan-3-ols from grape seed and skin into wine using simulated maceration. Analytica Chimica Acta, 513, 283-289.

Gordillo, B., Cejudo-Bastante, M. J., Rodríguez-Pulido, F. J., González-Miret, M. L., \& Heredia, F. J. (2013). Application of the differential colorimetry and polyphenolic profile to the evaluation of the chromatic quality of Tempranillo red wines elaborated in warm climate. Influence of the presence of oak wood chips during fermentation. Food Chemistry, 141, 2184-2190.

Gordillo, B., Rodríguez-Pulido, F. J., Mateus, N., Escudero-Gilete, M. L., GonzálezMiret, M. L., Heredia, F. J., et al. (2012). Application of LC-MS and tristimulus colorimetry to assess the ageing aptitude of Syrah wine in the Condado de Huelva D.O. (Spain), a typical warm climate region. Analytica Chimica Acta, 732, $162-171$.

Harborne, J. B. (1994). The flavonoids. Advances in research since 1986. 2-6 Boundary Row, London, England: Chapman \& Hall.

Hernández-Hierro, J. M., Nogales-Bueno, J., Rodríguez-Pulido, F. J., \& Heredia, F. J. (2013). Feasibility study on the use of near-infrared hyperspectral imaging for the screening of anthocyanins in intact grapes during ripening. Journal of Agricultural and Food Chemistry, 61, 9804-9809.

Hernández-Hierro, J. M., Quijada-Morín, N., Martínez-Lapuente, L., Guadalupe, Z. Ayestarán, B., Rivas-Gonzalo, J. C., et al. (2014). Relationship between skin cell wall composition and anthocyanin extractability of Vitis vinifera L. CV. Tempranillo at different grape ripeness degree. Food Chemistry, 146, 41-47.

Hernández-Hierro, J. M., Quijada-Morín, N., Rivas-Gonzalo, J. C., Rivas-Gonzalo, J. C., \& Escribano-Bailón, M. T. (2012). Influence of the physiological stage and the 
content of soluble solids on the anthocyanin extractability of Vitis vinifera L. cv. Tempranillo grapes. Analytica Chimica Acta, 732, 26-32.

Jackson, R. S. (2000). 6 - Chemical constituents of grapes and wine. In R. S. Jackson (Ed.), Wine science (2nd ed., pp. 232-280). San Diego: Academic Press.

Kontoudakis, N., Esteruelas, M., Fort, F., Canals, J. M., De Freitas, V., \& Zamora, F. (2011). Influence of the heterogeneity of grape phenolic maturity on wine composition and quality. Food Chemistry, 124, 767-774.

Nogales-Bueno, J., Hernández-Hierro, J. M., Rodríguez-Pulido, F. J., \& Heredia, F. J.

(2014). Determination of technological maturity of grapes and total phenolic compounds of grape skins in red and white cultivars during ripening by near infrared hyperspectral image: A preliminary approach. Food Chemistry, 152, 586-591.

Ribéreau-Gayon, P., Dubourdieu, D., Doneche, B., Lonvaud, A., Glories, Y., \& Maujean, A. (2006). Handbook of enology. The microbiology of wine and vinifications (Vol. 1). J. Wiley \& Sons.

Rice-Evans, C. A., Miller, J., \& Paganga, G. (1997). Antioxidant properties of phenolic compounds. Trends in Plant Science, 2, 152-159.

Rodríguez-Pulido, F. J., Hernández-Hierro, J. M., Nogales-Bueno, J., Gordillo, B., González-Miret, M. L., \& Heredia, F. J. (2014). A novel method for evaluating flavanols in grape seeds by near infrared hyperspectral imaging. Talanta, 122, 145-150.
Shenk, J. S., \& Westerhaus, M. O. (1995). Routine operation, calibration, development and network system management manual, NIRSystems. MD, USA: Silver Spring.

Singleton, V. L. (1985). Citation classic - colorimetry of total phenolics with phosphomolybdic-phosphotungstic acid reagents. Current Contents/Agriculture Biology E' Environmental Sciences, 18.

Torchio, F., Cagnasso, E., Gerbi, V., \& Rolle, L. (2010). Mechanical properties, phenolic composition and extractability indices of Barbera grapes of different soluble solids contents from several growing areas. Analytica Chimica Acta, 660, $183-189$.

Vivas, N., Glories, Y., Lagune, L., Saucier, C., \& Augustin, M. (1994). Estimation du degré de polymérisation des procyanidines du raisin et du vin par la méthode au p-dimethylaminocinnamaldéhyde. Journal International des Sciences de la Vigne et du Vin, 28, 319-336.

Waterhouse, A. L. (2002). Wine phenolics. New York: New York Acad Sciences.

Zouid, I., Siret, R., Jourjon, F., Mehinagic, E., \& Rolle, L. (2013). Impact of grapes heterogeneity according to sugar level on both physical and mechanical berries properties and their anthocyanins extractability at harvest. Journal of Texture Studies, 44, 95-103. 